\title{
Impact of the International Nosocomial Infection Control Consortium (INICC) Multidimensional Hand Hygiene Approach over 13 Years in 51 Cities of 19 Limited-Resource Countries from Latin America, Asia, the Middle East, and Europe
}

\author{
Victor D. Rosenthal, MD, MSc, CIC; ${ }^{1}$ Mandakini Pawar, MD; ${ }^{2}$ Hakan Leblebicioglu, MD; ${ }^{3}$ \\ Josephine Anne Navoa-Ng, MD; ${ }^{4}$ Wilmer Villamil-Gómez, MD; $;^{5}$ Alberto Armas-Ruiz, MD; ${ }^{6}$ Luis E. Cuéllar, MD; \\ Eduardo A. Medeiros, MD; Zan Mitrev, MD; ${ }^{8}$ Achilleas Gikas, MD; ${ }^{10}$ Yun Yang, MD; ${ }^{11}$ Altaf Ahmed, MD; ${ }^{12}$ \\ Souha S. Kanj, MD;13 Lourdes Dueñas, MD; ${ }^{14}$ Vaidotas Gurskis, MD; ${ }^{15}$ Trudell Mapp, RN; ${ }^{16}$ \\ Humberto Guanche-Garcell, MD; ${ }^{17}$ Rosalía Fernández-Hidalgo, RN; ${ }^{18}$
}

Andrzej Kübler, $\mathrm{MD}^{19}$

овјестіve. To assess the feasibility and effectiveness of the International Nosocomial Infection Control Consortium (INICC) multidimensional hand hygiene approach in 19 limited-resource countries and to analyze predictors of poor hand hygiene compliance.

DESIGN. An observational, prospective, cohort, interventional, before-and-after study from April 1999 through December 2011 . The study was divided into 2 periods: a 3-month baseline period and a 7-year follow-up period.

Setting. Ninety-nine intensive care unit (ICU) members of the INICC in Argentina, Brazil, China, Colombia, Costa Rica, Cuba, El Salvador, Greece, India, Lebanon, Lithuania, Macedonia, Mexico, Pakistan, Panama, Peru, Philippines, Poland, and Turkey.

PARTICIPANTS. Healthcare workers at 99 ICU members of the INICC.

METHODS. A multidimensional hand hygiene approach was used, including (1) administrative support, (2) supplies availability, (3) education and training, (4) reminders in the workplace, (5) process surveillance, and (6) performance feedback. Observations were made for hand hygiene compliance in each ICU, during randomly selected 30-minute periods.

RESULTS. A total of 149,727 opportunities for hand hygiene were observed. Overall hand hygiene compliance increased from $48.3 \%$ to $71.4 \%(P<.01)$. Univariate analysis indicated that several variables were significantly associated with poor hand hygiene compliance, including males versus females $(63 \%$ vs $70 \% ; P<.001)$, physicians versus nurses $(62 \%$ vs $72 \% ; P<.001)$, and adult versus neonatal ICUs $(67 \%$ vs $81 \% ; P<.001)$, among others.

CONCLUSIONs. Adherence to hand hygiene increased by $48 \%$ with the INICC approach. Specific programs directed to improve hand hygiene for variables found to be predictors of poor hand hygiene compliance should be implemented.

Infect Control Hosp Epidemiol 2013;34(4):415-423

The impact of hand hygiene before patient contact for infection prevention was demonstrated 160 years ago when Semmelweis studied the relationship between improved hand antisepsis and reduced mortality from puerperal sepsis. ${ }^{1}$ Since then, it has been reported that improved hand hygiene prac- tice reduces healthcare-associated infection (HAI) rates and antimicrobial resistance. ${ }^{2-4}$

HAIs threaten patient safety and cause patient morbidity and mortality. ${ }^{5}$ Most studies of HAIs are from developed countries; ${ }^{6}$ in limited-resource countries (LRCs), this problem

Affiliations: 1. International Nosocomial Infection Control Consortium, Buenos Aires, Argentina; 2. Pushpanjali Crosslay Hospital, Ghaziabad, India; 3. Ondokuz Mayis University Medical School, Samsun, Turkey; 4. St. Luke's Medical Center, Quezon City, Philippines; 5. Clínica Santa María, Sucre, Colombia; 6. Centro Médico La Raza IMSS, Mexico City, Mexico; 7. Instituto Nacional de Enfermedades Neoplásicas, Lima, Peru; 8. Hospital São Paulo, São Paulo, Brazil; 9. Special Hospital for Surgical Disease "Filip Vtori," Skopje, Macedonia; 10. University Hospital of Heraklion, Heraklion, Greece; 11. Shanxi Dayi Hospital, Tai Yuan, China; 12. Indus Hospital, Karachi, Pakistan; 13. American University of Beirut Medical Center, Beirut, Lebanon; 14. Hospital Nacional de Niños Benjamin Bloom, San Salvador, El Salvador; 15. Pediatric Clinic, Lithuanian University of Health Sciences, Kaunas, Lithuania; 16. Clínica Hospital San Fernando, Panama City, Panama; 17. Hospital Docente Clínico Quirúrgico "Joaquín Albarrán Domínguez," Havana, Cuba; 18. Hospital Clínica Bíblica, San José, Costa Rica; 19. University Hospital of Wroclaw, Wroclaw, Poland.

Received September 7, 2012; accepted November 12, 2012; electronically published February 14, 2013.

(C) 2013 by The Society for Healthcare Epidemiology of America. All rights reserved. 0899-823X/2013/3404-0013\$15.00. DOI: 10.1086/669860 
had not been systematically addressed until the International Nosocomial Infection Control Consortium (INICC) started analyzing and publishing HAI rates determined using standardized definitions and methods. ${ }^{7-11}$

Hand hygiene remains the cornerstone in cross HAI prevention among patients. Successful interventions to improve hand hygiene have been reported from high-income countries $^{12}$ and from limited-resource countries. ${ }^{3,13,14}$ From the 1980s, investigators have analyzed the effectiveness of interventions to improve hand hygiene, including the impact of supplies availability, published by Preston et a ${ }^{15}$ in 1981; the use of reminders and posters in the workplace, published by Conly et $\mathrm{a}^{16}$ in 1989; the use of monitoring and performance feedback, published by Mayer et $\mathrm{al}^{17}$ in 1986; administrative support, published by Larson et $\mathrm{al}^{18}$ in 1997; the introduction of alcohol-based hand rub (AHR), published by $\mathrm{Graham}^{19}$ in 1990; and the effectiveness of education, published by Dubbert et $\mathrm{al}^{20}$ in 1990 and by Dorsey et $\mathrm{al}^{21}$ in 1996. The 1997 study by Larson et a $\mathrm{l}^{18}$ explicitly referred to a multidimensional approach that considered several interventions in a study conducted in the United States. Likewise, Rosenthal and colleagues have implemented programs in Argentina since 1993 combining administrative support, supplies availability, education and training, process surveillance, and performance feedback, which produced a sustained improvement in hand hygiene compliance ${ }^{3,13}$ with a reduction in HAI rates. $^{3}$

The US Centers for Disease Control and Prevention (CDC) published its hand hygiene guideline in 2002. ${ }^{22}$ In 2005, the World Health Organization (WHO) launched the program Clean Care Is Safer Care to promote hand hygiene worldwide. ${ }^{23}$ In 2009, the WHO published its guidelines, which included a combination of previously published data and a new formulation for AHR products, among several other recommendations. $^{4}$

The purpose of this INICC study was to establish the baseline hand hygiene compliance rate by healthcare workers (HCWs) before patient contact, analyze risk factors for poor adherence, and implement and evaluate the impact of an INICC multidimensional hand hygiene approach (IMHHA) in hospitals from 19 limited-resource countries. The IMHHA includes the following elements: (1) administrative support, (2) supplies availability, (3) education and training, (4) reminders in the workplace, (5) process surveillance, and (6) performance feedback.

\section{METHODS}

\section{Background on the INICC}

The INICC is an international, nonprofit, open, multicenter HAI surveillance network with a methodology based on the US CDC's National Healthcare Safety Network. ${ }^{24}$ The INICC is the first research network established to measure and control HAIs in hospitals through the analysis of standardized data collected on a voluntary basis by its member hospitals.
Gaining new members since its international inception in 2002 , the INICC is now composed of nearly 1,000 hospitals in 200 cities of 43 limited-resource countries in Latin America, Asia, Africa, the Middle East, and Europe and has become the only source of aggregate standardized international data on the epidemiology of HAIs from limited-resource countries. ${ }^{11}$

\section{Study Setting}

This study was conducted in 99 ICUs of 65 INICC member hospitals from 51 cities of 19 countries (Argentina, Brazil, China, Colombia, Costa Rica, Cuba, El Salvador, Greece, India, Lebanon, Lithuania, Macedonia, Mexico, Pakistan, Panama, Peru, Philippines, Poland, and Turkey), which were successively incorporated into the study over a period of almost 13 years. Each hospital has an infection control team (ICT) composed of at least 1 infection control practitioner and 1 physician. The HCW in charge of process surveillance at each hospital has at least 2 years of infection control experience. The study protocol was approved by the institutional review boards at each hospital, and patient confidentiality was protected by codifying the recorded information, making it identifiable only to the ICT.

\section{Study Design}

An observational, prospective, cohort, interventional, beforeand-after multicenter study was conducted from April 1999 through December 2011. The study was divided into 2 periods: baseline and follow-up. The baseline period for hand hygiene compliance included episodes documented at each hospital during its first 3 months of participation, and the follow-up period included episodes following the fourth month of participation.

\section{IMHHA}

The IMHHA is implemented at each hospital from the beginning of its participation in the INICC. The approach includes the following 6 components: (1) administrative support, (2) supplies availability, (3) education and training, (4) reminders in the workplace, (5), process surveillance, and (6) performance feedback. Although the components are presented individually, they are interactive elements that must concur for the effective implementation of any "multidimensional" approach.

Administrative support. Hospital administrators of the participating hospitals agreed and committed to the study, attended infection control meetings to discuss study findings, and allocated supplies of hand hygiene products.

Supplies availability. During the study period, AHR bottles were available at the entrances of ICUs, nursing stations, and near the site of patient care (individual patient room entrances, bedside tables, and/or the feet of patient beds). Sinks with water supply, soap, and paper towels were available 
TABLE 1. Characteristics of the Participating Hospitals (from April 1999 through December 2011)

\begin{tabular}{|c|c|c|}
\hline & Value & $\begin{array}{c}\text { No. of } \\
\text { observation }\end{array}$ \\
\hline \multicolumn{3}{|l|}{ No. of ICUs by country } \\
\hline Argentina & 11 & 21,998 \\
\hline Brazil & 4 & 4,837 \\
\hline China & 5 & 2,079 \\
\hline Colombia & 11 & 13,512 \\
\hline Costa Rica & 1 & 303 \\
\hline Cuba & 1 & 434 \\
\hline El Salvador & 3 & 1,691 \\
\hline Greece & 1 & 2,315 \\
\hline India & 18 & 32,869 \\
\hline Lebanon & 1 & 1,728 \\
\hline Lithuania & 1 & 1,565 \\
\hline Macedonia & 1 & 3,418 \\
\hline Mexico & 10 & 13,201 \\
\hline Pakistan & 3 & 1,830 \\
\hline Panama & 1 & 551 \\
\hline Peru & 5 & 6,610 \\
\hline Philippines & 9 & 17,844 \\
\hline Poland & 1 & 102 \\
\hline Turkey & 12 & 22,840 \\
\hline All countries & 99 & 149,727 \\
\hline \multicolumn{3}{|l|}{ Type of ICU, no. (\%) } \\
\hline Adult & $80(81)$ & 131,882 \\
\hline Pediatric & $9(9)$ & 9,081 \\
\hline Newborn & $10(10)$ & 8,764 \\
\hline All ICUs & $99(100)$ & 149,727 \\
\hline \multicolumn{3}{|c|}{ Type of hospital, no. (\%) } \\
\hline Academic teaching & $27(42)$ & 50,515 \\
\hline Public & $16(25)$ & 40,530 \\
\hline Private community & $22(34)$ & 58,682 \\
\hline All hospitals & $65(100)$ & 149,727 \\
\hline
\end{tabular}

Nore. ICU, intensive care unit.

at the entrances of ICUs, nursing stations, and common areas of ICUs.

Education and training. At the study's ICUs, the ICT members provided 30 -minute education sessions to HCWs during each work shift, at the beginning of the study period, and periodically during the follow-up period. Education included basic information about indications of hand hygiene and the correct procedures and technique for hand hygiene.

Reminders in the workplace. Poster reminders were displayed all around the hospital settings (ie, hospital entrance, corridors, ICT office, ICU entrances, nursing stations, beside each sink, and beside each AHR bottle). They included simple instructions on hand hygiene performance, in line with the contents of the education and training program.

Process surveillance. Process surveillance of hand hygiene practices consisted of the registrations of potential opportunities for hand hygiene 4 and the actual number of hand hygiene episodes, either with soap and water or AHR. HCWs' hand hygiene practice was directly monitored by an observer (a member of the ICT) following a standardized protocol and completing hand hygiene process surveillance INICC forms. ${ }^{7}$ Observations were conducted unobtrusively at specific time periods distributed over 3 work shifts (morning, afternoon, and evening). HCWs were not aware of the schedule of the monitoring period. The monitoring included hand hygiene compliance before patient contact and before an aseptic task. Potential confounders of hand hygiene included type of ICU, professional category, sex, work shift, and type of contact.

Performance feedback. Every month, the INICC headquarters team prepares and sends to each participating ICU a final month-by-month report on compliance with hand hygiene. These charts contain a running tally of hand hygiene compliance by HCWs of the ICUs and compliance comparing several variables, such as sex, HCW professional status, ICU type, contact type, and work shift. Those charts were reviewed at monthly ICT meetings and were also posted in the ICUs to give performance feedback to the HCWs of the participating ICUs. ${ }^{7}$ The performance feedback process started on average at the third month of participation.

\section{Training of the ICT for Process Surveillance}

The ICT member investigators were self-trained by means of a procedure manual sent from the INICC headquarters in Buenos Aires specifying how to carry out the hand hygiene process surveillance and how to fill in the INICC forms. ICT members had continuous telephone or e-mail access to a support team at the INICC headquarters.

\section{Data Collection and Processing}

Completed INICC process surveillance forms for hand hygiene were sent monthly by ICT members from each participating ICU to the INICC headquarters. The team at the INICC headquarters uploaded the data into a database, analyzed the data, and sent to ICT members of each participating ICU a report on hand hygiene compliance showing hand hygiene compliance by month, sex, HCW profession, ICU, work shift, and type of contact. ${ }^{7}$

\section{Statistical Methods}

Univariate analysis of variables associated with poor hand hygiene and of the impact of the hand hygiene approach. The aggregated independent variables (sex of HCWs, profession of HCWs, type of ICU, type of contact, etc) of all observed hand hygiene opportunities and hand hygiene compliance during the whole study and hand hygiene compliance during the baseline period versus that during the follow-up period were compared using the Fisher exact test for dichotomous variables and the unmatched Student $t$ test for continuous variables. Relative risk (RR) ratios were calculated for comparisons of analyzed variables associated with hand hygiene using Epi Info, version 6 (CDC); VCStat (Castiglia) was used to calculate $95 \%$ confidence intervals (CIs). Differences with 
TABLE 2. Distribution of Hand Hygiene (HH) Compliance by Type of Intensive Care Unit (ICU)

\begin{tabular}{lcccc}
\hline ICU type & No. of ICUs & $\begin{array}{c}\text { No. of } \\
\text { opportunities for HH }\end{array}$ & $\begin{array}{c}\text { No. of } \\
\text { HH compliances }\end{array}$ & $\begin{array}{c}\text { HH compliance, } \\
\text { mean \% (95\% CI) }\end{array}$ \\
\hline Burn & 1 & 1,324 & 1,176 & $89(87-90.5)$ \\
Medical cardiac & 7 & 16,067 & 10,729 & $64(63.4-64.9)$ \\
Cardiosurgical & 3 & 4,975 & 3,943 & $79(78.1-80.4)$ \\
Medical & 4 & 8,873 & 7,150 & $81(79.7-81.4)$ \\
Medical-surgical & 48 & 74,683 & 46,547 & $62(62.0-62.7)$ \\
Newborn & 9 & 8,764 & 7,101 & $81(80.2-81.8)$ \\
Neurosurgical & 6 & 9,715 & 7,767 & $80(79.1-80.7)$ \\
Pediatric & 10 & 9,081 & 6,443 & $71(70-71.9)$ \\
Respiratory & 1 & 413 & 272 & $66(61.1-70.4)$ \\
Surgical & 8 & 8,299 & 4,963 & $60(58.7-60.9)$ \\
Trauma & 1 & 6,671 & 5,449 & $82(80.7-82.6)$ \\
Ward & 1 & 862 & 757 & $88(85.4-89.9)$ \\
All & 99 & 149,727 & 101,877 & $68(67.8-68.3)$ \\
\hline
\end{tabular}

NOTE. CI, confidence interval.

$P$ values less than .05 by 2 -tailed tests were considered significant.

Multivariate analysis of variables associated with poor hand hygiene. The aggregated described independent variables of all observed hand hygiene opportunities and hand hygiene compliance during the whole study were compared using logistic regression for dichotomous and continuous variables. Odds ratios with $95 \%$ CIs were calculated for comparisons of analyzed variables associated with hand hygiene using

TABLE 3. Hand Hygiene ( $\mathrm{HH})$ Compliance by Type of VariableUnivariate Analysis

\begin{tabular}{lclcc}
\hline Variable & HH $\%^{\mathrm{a}}$ & Comparison & $\mathrm{RR}(95 \% \mathrm{CI})$ & $P$ \\
\hline $\begin{array}{l}\text { Sex } \\
\text { Female }\end{array}$ & 70 & F vs M & $0.90(0.89-0.91)$ & .0001 \\
$\quad$ Male & 63 & & & \\
HCW & & & & \\
$\quad$ Nurses & 72 & Ns vs Ph & $0.86(0.85-0.88)$ & .0001 \\
$\quad \begin{array}{l}\text { Physicians } \\
\text { Ancillary staff }\end{array}$ & 62 & Ns vs AS & $0.78(0.77-0.80)$ & .0001 \\
Procedure & 57 & Ph vs AS & $0.91(0.89-0.93)$ & .0001 \\
$\quad$ Noninvasive & 68 & Ni vs I & $0.98(0.97-0.99)$ & .0037 \\
$\quad$ Invasive & 69 & & & \\
ICU type & & & & \\
$\quad \begin{array}{l}\text { Adult } \\
\text { Pediatric }\end{array}$ & 67 & Ad vs Pe & $0.94(0.92-0.97)$ & .0001 \\
$\quad$ Newborn & 81 & Ad vs Nb & $0.83(0.81-0.85)$ & .0001 \\
Work shift & & Nb vs Pe & $0.88(0.85-0.91)$ & .001 \\
$\quad$ Morning & 67 & Mo vs Af & $1.00(0.99-1.02)$ & .7926 \\
Afternoon & 67 & Mo vs Nt & $0.92(0.91-0.94)$ & .0001 \\
Night & 72 & Af vs Nt & $0.92(0.91-0.94)$ & .0001 \\
\hline
\end{tabular}

NoTe. Ad, adult; Af, afternoon work shift; AS, ancillary staff; CI, confidence interval; $\mathrm{F}$, female; HCW, healthcare worker; I, invasive; ICU, intensive care unit; $\mathrm{M}$, male; Mo, morning work shift; $\mathrm{Nb}$, newborn; $\mathrm{Ni}$, noninvasive; $\mathrm{Ns}$, nurses; $\mathrm{Nt}$, night work shift; $\mathrm{Pe}$, Pediatric; $\mathrm{Ph}$, physicians; $\mathrm{RR}$, relative risk.

a No. of $\mathrm{HH}$ compliance/no. of $\mathrm{HH}$ opportunities.
PASW Statistics 18. Differences with $P$ values less than .05 by 2 -tailed tests were considered significant.

Multivariate analysis of the impact of the IMHHA. Hand hygiene opportunities and hand hygiene compliance during baseline and follow-up were explored for changes in hand hygiene compliance rates following an ICU joining the INICC. We looked at the follow-up period stratified by 3 month periods over the first year, yearly for the second and third year of participation, and every 2 years from the fourth to the seventh year. We present the results of a logistic regression model to consider change in hand hygiene compliance in INICC-participating ICUs over time since the beginning of the hand hygiene surveillance. Odds ratios are presented, comparing each time period since the start of the surveillance with the average baseline of 3 months. This is a large data set, with $\sim 150,000$ observations, and so we were able to adjust for the effect of each ICU on hand hygiene compliance as a categorical variable in the analysis. Because of the different length of follow-up for each ICU (from 1 month to 7 years), for each time period only ICUs with follow-up in that time period were included in the baseline period used for calculating the odds ratio of hand hygiene compliance for that period.

\section{RESULTS}

From April 1999 through December 2011 (12 years and 9 months), we recorded a total 149,727 opportunities for hand hygiene before patient contact and before an aseptic task. Characteristics of participating hospitals are shown in Table 1.

\section{Predictors of Poor Hand Hygiene Compliance}

We observed 41,759 procedures in males and 76,645 in females; 97,450 in nurses, 28,609 in physicians, and 23,668 in ancillary staff; 105,181 prior to noninvasive patient contacts and 40,548 prior to invasive procedures; 131,822 in adult ICUs, 9,081 in pediatric ICUs, and 8,764 in neonatal ICUs; 
TABLE 4. Hand Hygiene Compliance by Variable-Logistic Regression, Multivariate Analysis

\begin{tabular}{llc}
\hline Variable & Adjusted OR (95\% CI) & $P$ \\
\hline $\begin{array}{l}\text { Sex } \\
\text { Baseline: female }\end{array}$ & 1.0 & \\
$\quad$ Male & $0.91(0.89-0.93)$ & $<.001$ \\
Type of professional & & \\
$\quad$ Baseline: nurses & 1.0 & \\
$\quad$ Physicians & $0.68(0.66-0.70)$ & $<.001$ \\
Ancillary staff & $0.52(0.51-0.54)$ & $<.001$ \\
Type of procedure & & \\
Baseline: invasive & 1.0 & \\
$\quad$ Noninvasive & $0.95(0.93-0.98)$ & $<.001$ \\
Type of ICU & & \\
Baseline: newborn & 1.0 & $<.001$ \\
Adult & $0.49(0.47-0.52)$ & $<.001$ \\
Pediatric & $0.58(0.54-0.62)$ & \\
Work shift & & $<.001$ \\
Baseline: night & 1.0 & $<.001$ \\
Afternoon & $0.79(0.76-0.81)$ & \\
Morning & $0.83(0.81-0.86)$ & \\
\hline
\end{tabular}

NoTE. CI, confidence interval; ICU, intensive care unit; $O R$, odds ratio.

and 68,584 during the morning shift, 46,741 during the afternoon shift, and 34,402 during the night shift. Table 2 shows hand hygiene compliance distribution among the different ICU types. Tables 3 and 4 show hand hygiene compliance according to each variable (sex, HCW professional status, type of procedure, type of ICU, and work shift) and association with poor hand hygiene, analyzed by univariate and multivariate statistical methods.

\section{Components of the IMHHA}

During the follow-up period, the 6 components of the IMHHA were applied simultaneously: $97 \%$ counted on administrative support and available supplies for hand hygiene and AHR; $98.5 \%$ educated HCWs $(48.5 \%$ of them every month, $12.1 \%$ every 2 months, $15.2 \%$ every 3 months, $10.6 \%$ every 6 months, and $13.6 \%$ every year); $96 \%$ posted reminders $(81.8 \%$ of them at the ICU entrance, $89.9 \%$ in common ICU areas, and $14.1 \%$ beside each bed); $100 \%$ conducted process surveillance; and $90.9 \%$ provided performance feedback $(57 \%$ every month, $7 \%$ every 2 months, $18 \%$ every 3 months, $12 \%$ every 6 months, and $7 \%$ every year).

\section{Impact of the IMHHA on Hand Hygiene Compliance}

The average baseline period of the INICC ICUs was 3 months (range, 1-3 months), and their average follow-up period was 23.9 months (range, 1-80 months). Hand hygiene before patient contact or an aseptic task was $48.3 \%$ (95\% CI, 47.6\%48.9\%) during baseline and $71.4 \%$ (95\% CI, 71.2\%-71.6\%) during follow-up (RR, 1.47 [95\% CI, 1.45-1.51]; $P<.01$; Table 5). In Table 5, we present the results of a logistic regression model to consider change in hand hygiene compliance in INICC-participating ICUs over the whole study period.

\section{Use of Hand Hygiene Products over Time}

Use of aqueous chlorhexidine for hand washing was $100 \%$ in 1999 , with a gradual reduction to $30 \%$ by 2005 and a final reduction to $20 \%$ in 2011 . AHR use started in 2001, with variations from $5 \%$ to $25 \%$ from 2005 to 2010 and rise to $55 \%$ in 2011 (Figure 1).

\section{DISCUSSION}

Baseline hand hygiene compliance $(48.3 \%)$ of HCWs at INICC ICUs was similar to that shown in previous studies, whose hand hygiene compliance rates ranged from $9 \%$ to $75 \% .{ }^{4}$ There was higher compliance among females, as also identified among individuals unrelated to health care, such as the findings of Guinan et $\mathrm{a}^{25}$ showing higher compliance by female students. Compliance was higher among nurses, as also shown in a study by Rosenthal et $\mathrm{al}^{3}$ in 2005 , in which compliance was lower among physicians and ancillary staff than among nurses. Morning and afternoon shifts were significantly associated with lower hand hygiene compliance compared with the night shift. This can be explained by the fact that ICUs are more crowded and busy during day shifts than night shifts. In 1982, Haley and Bregman ${ }^{26}$ showed that overcrowding and understaffing hindered the efforts of HCWs to perform hand hygiene. We also showed that the highest hand hygiene compliance was in neonatal ICUs. Watanakunakorn et $\mathrm{al}^{27}$ found remarkable variations by unit, with compliance being $56 \%$ in ICUs compared with $23 \%$ in non-ICUs. We also showed that type of contact influenced hand hygiene performance: superficial contacts were associated with lower compliance. Lipsett and Swoboda ${ }^{28}$ showed that lower hand hygiene compliance was found in low-risk situations.

Use of hand hygiene products changed, showing an increase in AHR use and a reduction in chlorhexidine use. This could be related to increasingly wider promotion of AHR by the WHO. ${ }^{4}$

Our approach included administrative support. In 2003, Rosenthal et $\mathrm{al}^{13}$ showed that higher hand hygiene adherence was associated with administrative support. We also included supplies availability. In 2000 , Bischoff et $\mathrm{al}^{29}$ demonstrated the effect of easily accessible AHR dispensers and revealed that the more dispensers per bed, the higher the hand hygiene compliance. We also included education and training, which were other basic independent interventions identified to foster adequate hand hygiene performance. As shown in 1990 by Dubbert et al, ${ }^{20}$ an educational intervention including routine classes improved hand hygiene compliance by $97 \%$ over 4 weeks. Likewise but within the context of limited-resource countries, Rosenthal et $\mathrm{al}^{13}$ showed that education of HCWs improved hand hygiene adherence and that compliance increased further if performance feedback was also imple- 
mented. We also included reminders at the workplace. In 1989 , Conly et $\mathrm{a}^{16}$ showed the importance of reminders to raise the awareness of HCWs regarding the relationship between correct hand hygiene performance and HAI reduction.

We measured almost 150,000 opportunities for hand hygiene. Every month, the ICT provided performance feedback to HCWs of each ICU. This is a very motivating aspect of the IMHHA for HCWs. Knowing the outcome of their efforts reflected by the measurement of their practices and HAI incidence can be a most rewarding or consciousness-raising factor to ensure the IMHHA's effectiveness. Providing continuous feedback to industrial workers of the results of monitoring the quality of the final product to improve product quality stems from the epochal contributions of Deming. ${ }^{30}$ Beginning in 1998 in Argentina ${ }^{3,13,31-33}$ and in 2002 internationally, ${ }^{7-11}$ the INICC has introduced process surveillance and performance feedback as a means to raise quality in health care to a new level, monitoring and providing continuous feedback not only of outcome data (rates of HAI) but also of the results of process surveillance (rates of hand hygiene compliance and other simple but highly effective evidence-based infection control practices), and it has shown that combining education with feedback of surveillance can bring about quantum reductions in the risk of life-threatening HAIs in ICUs. ${ }^{3,13}$

In this study of a large and remarkably diverse ICU population from 51 cities of 19 countries, we have shown that implementing the above-described 6 measures of the IMHHA in each ICU was followed by very substantial improvements in hand hygiene practices. Through the last decade, the INICC has undertaken a global effort in America, Asia, Africa, the Middle East, and Europe to respond to the burden of HAIs and has achieved extremely successful results by increasing hand hygiene compliance, improving compliance with other infection control interventions as described in several INICC publications, and consequently reducing the rates of $\mathrm{HAI}$ and mortality. Since 2002, in adult ICUs in 15 countries, the INICC has reduced the rate of central line-associated bloodstream infection (CLABSI) by $54 \%,{ }^{34}$ of catheter-associated urinary

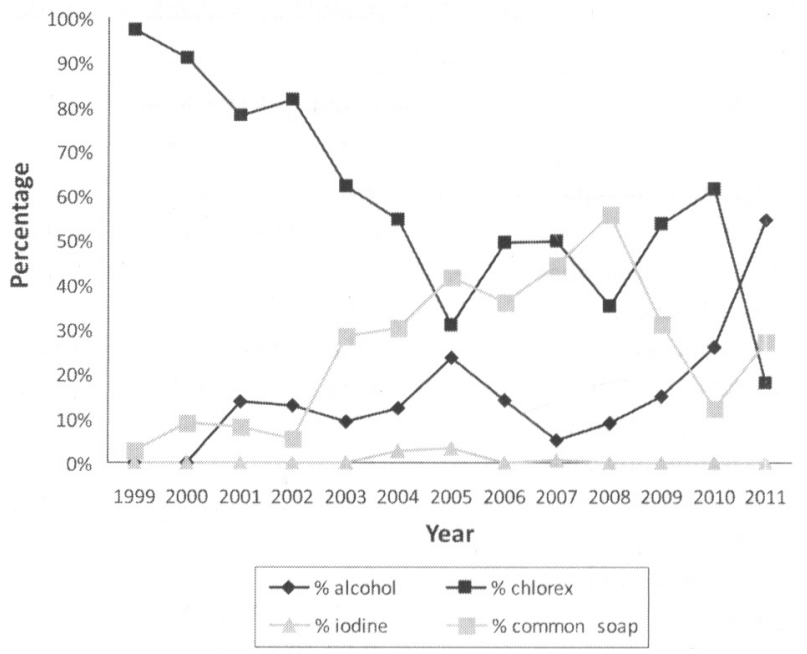

FIGURE 1. Type of product used for hand hygiene over the years of participation.

tract infection (CAUTI) by $37 \%,{ }^{35}$ of ventilator-associated pneumonia (VAP) by $56 \%,{ }^{36}$ and of mortality by $58 \%{ }^{34}$ In pediatric ICUs in 5 countries, the INICC has reduced the rate of CLABSI by $52 \%,{ }^{37}$ of CAUTI by $57 \%,{ }^{38}$ of VAP by $31 \%,{ }^{39}$ and of mortality by $31 \% \cdot{ }^{37}$ In neonatal ICUs in 10 countries, the INICC has reduced the rate of VAP by $33 \%{ }^{40}$

There are several limitation to this study, such as the INICC not measuring the My 5 Moments for Hand Hygiene as advised recently by the WHO. This is because the INICC started the IMHHA in 1998 in Argentina, ${ }^{3,13}$ and in 2002 internationally, ${ }^{7}$ several years before the recommendation of the WHO was published in 2009; however, since 2009 the INICC has included the WHO's My 5 Moments for Hand Hygiene in its process surveillance forms and manuals. ${ }^{4}$ In addition, it should be noted that this study used an observational, before-and-after methodology, which generates less strength and quality of evidence than other study designs. Direct ob-

TABLE 5. Hand Hygiene ( $\mathrm{HH})$ Improvement by Year of Participation

\begin{tabular}{lcccc}
\hline Time since joining INICC & $\begin{array}{c}\text { No. of } \\
\text { HH observations }\end{array}$ & $\begin{array}{c}\text { No. of } \\
\text { ICUs included }\end{array}$ & $\begin{array}{c}\text { HH \% } \\
(95 \% \mathrm{CI})\end{array}$ & $\begin{array}{c}\text { Adjusted OR } \\
(95 \% \mathrm{CI})\end{array}$ \\
\hline First 3 months (baseline) & 11,267 & 99 & $48.3(47.6-49.0)$ & 1.0 \\
Second 3 months & 7,214 & 99 & $61.2(60.5-61.9)$ & $1.72(1.65-1.81)$ \\
Third 3 months & 5,511 & 89 & $67.2(66.4-67.8)$ & $2.10(1.99-2.2)$ \\
Fourth 3 months & 4,639 & 81 & $69.4(68.6-70.1)$ & $2.21(2.10-2.33)$ \\
Second year & 8,190 & 69 & $71.4(70.9-71.9)$ & $3.07(2.92-3.23)$ \\
Third year & 5,573 & 45 & $69.1(68.4-69.7)$ & $3.03(2.84-3.22)$ \\
Fourth and fifth years & 4,278 & 32 & $81.2(80.1-81.6)$ & $3.30(3.07-3.52)$ \\
Sixth and seventh years & 1,120 & 15 & $86.0(85.2-86.8)$ & $2.87(2.57-3.19)$ \\
Considering time since follow-up as a continuous & & & & \\
$\quad$ variable per year of participation & 149,727 & 99 & $68.0(67.8-68.3)$ & $1.27(1.25-1.28)$ \\
\hline
\end{tabular}

NoTE. Comparisons were made using only intensive care units (ICUs) with follow-up. That is, for comparison of hand hygiene compliance with baseline for the third year, only hospitals with at least 3 years of follow-up were included, and so on for the following periods. CI, confidence interval; INICC, International Nosocomial Infection Control Consortium; OR, odds ratio. 
servation of adherence typically involves a Hawthorne effect, represents only a sample of all opportunities, and has inherent weaknesses, including assuring interobserver reliability, especially given the broad scope of this research in terms of facilities and countries. It should also be noted that the quality of hand hygiene technique is hard to capture, and we were not able to include many details in this investigation. Finally, we did not include in this study information on HAI and mortality rates, since there are several INICC publications focusing in these topics in relation to hand hygiene.

In conclusion, it has been demonstrated that the IMHHA improved hand hygiene compliance in limited-resource countries of 4 continents and contributed to the reduction of $\mathrm{HAI}$ rates and mortality rates. ${ }^{11,34,36,37,39,40}$ It is the INICC's primary objective to foster infection control practices by freely facilitating elemental and inexpensive resources and tools to tackle this problem effectively and systematically, leading to greater and steady adherence to infection control programs and guidelines, such as hand hygiene compliance, and to the correlated reduction in HAIs and their consequences, such as mortality and extra cost.

\section{OTHER INICC INVESTIGATORS/COAUTHORS}

\section{PARTICIPATING IN THIS STUDY}

Argentina. Mónica Viegas, Beatriz Marta Alicia Di Núbila, Diana Lanzetta, Leonardo J. Fernández, María Adelaida Rossetti, Adriana Romani, Claudia Migazzi, Clarisa Barolin, Estela Martínez (Hospital Interzonal General de Agudos Presidente Perón, Avellaneda); Daniel Sztokhamer (Clínica Estrada, Buenos Aires); Guillermo Benchetrit, Claudio Bonaventura, Maria de los Ángeles Caridi, Adriana Messina, Beatriz Ricci (Centro Gallego de Buenos Aires, Buenos Aires); Luisa C. Soroka (Hospital Interzonal General de Agudos Evita, Lanús); Carlos Esteban Lastra (Hospital Narciso López, Lanús); Adriana Romani, María Laura Frías (Clínica Modelo Imagmed S. A., Lanús).

Brazil. Daniela Bicudo Angelieri (Hospital São Paulo, São Paulo); Gorki Grinberg (Hospital General Porto Alegre, Porto Alegre; Hospital Universitario Santa Terezinha, Joaçaba); Iselde Buchner Ferreira, Raquel Bauer Cechinel (Hospital General Porto Alegre, Porto Alegre); Jamile Leda Spessatto (Hospital Universitario Santa Terezinha, Joaçaba); Bruna Boaria Zanandrea, Carolina Rohnkohl, Marcos Regalin (Hospital Sao Miguel, Joaçaba).

China. Su Danxia, Hao Chunxia, Pan Wei (Shanxi Dayi Hospital, Tai Yuan); Hu Bijie, Xiandong Gao (Zhongshan Hospital, Fudan University, Shanghai); Tao Lili (Zhongshan Hospital, Fudan University); Liu Kun, Li Ruisheng (Chaoyang Hospital, Beijing).

Colombia. Antonio Menco, Patrick Arrieta (Clínica Santa María, Sucre); Nayide Barahona-Guzmán, Marena Rodríguez-Ferrer, Guillermo Sarmiento-Villa, Alfredo LagaresGuzmán (Universidad Simón Bolívar, Barranquilla); María Eugenia Rodríguez-Calderón (Hospital La Victoria, Bogotá);
Luis Dajud Casas, Patricia Garrido (Clínica de la Sabana, Sucre); Narda Olarte, Alberto Valderrama (Hospital El Tunal ESE, Bogotá); Luis Carlos Surigue Dojulo, Remberto Oviedo Contreras (Hospital Universitario de Sincelejo, Sincelejo); Catherine Rojas, Alejandra Sabogal, Yulieth Carvajal, Edwin Silva Infectólogo (Centro Policlínico del Olaya, Bogota).

Costa Rica. Juan Manuel Aragón-Calzada, Gabriel Muñoz y Adela Ruiz-Argüello (Hospital Clínica Bíblica, San Jose).

Cuba. Clara Morales-Pérez (Hospital Docente Clínico Quirúrgico "Joaquín Albarrán Domínguez," Havana).

Greece. Kalliopi Chaniotaki, Constantinos Tsioutis, Dimitris Bampalis (University Hospital of Heraklion, Heraklion).

El Salvador. Ana Concepción Bran de Casares, Lilian de Jesús Machuca (Hospital Nacional de Niños Benjamin Bloom, Hospital Nacional de Niños Benjamin Bloom).

India. Amit Gupta, Narinder Saini (Pushpanjali Crosslay Hospital, Ghaziabad); Subhash Kumar Todi, Mahuya Bhattacharyya, Arpita Bhakta (AMRI Hospitals, Kolkata); Murali Chakravarthy, B. N. Gokul, Sukanya R., Leema Pushparaj (Wockhardt Hospitals, Bangalore); Sheila Nainan Myatra, J. V. Divatia, Rohini Kelkar, Sanjay Biswas, Sandhya Raut, Sulochana Sampat (Tata Memorial Hospital, Mumbai); Anil Karlekar (Escorts Heart Institute and Research Centre, New Delhi); Sanjeev Singh, Kavitha Radhakrishnan (Amrita Institute of Medical Sciences and Research Center, Kochi); F. E. Udwadia, Aruna Poojary, Geeta Koppikar, Lata Bhandarkar, Shital Jadhav, Shweta Bahirune, Shilpa Durgad (Breach Candy Hospital Trust, Mumbai); Arpita Dwivedy, Suvin Shetty, Sheena Binu, Preethi Pinto (Dr L. H. Hiranandani Hospital, Mumbai).

Lebanon. Nada Zahreddine, Lamia Alamuddin, Zeina Kanafani, Bassel Molaeb (American University of Beirut Medical Center, Beirut).

Lithuania. Algirdas Dagys, Tomas Kondratas, Rimantas Kevalas (Pediatric Clinic, Lithuanian University of Health Sciences, Kaunas).

Macedonia. Tanja Anguseva, Vilma Ampova, Snezana Tufekcievska Guroska, Zaneta Bogoevska-Miteva (Special Hospital for Surgical Disease "Filip Vtori," Skopje).

Mexico. Roberto Campuzano, Jorge Mena Brito (Centro Médico La Raza IMSS, México DF); Martha SobreyraOropeza (Hospital de la Mujer, México DF); Francisco Higuera (Hospital General de México, México DF); Irma Pérez-Serrato, Martha Sánchez-López (Hospital General de la Celaya, Celaya); Héctor Torres-Hernández, Amalia ChávezGómez, Jaime Rivera-Morales, Julián Enrique ValeroRodríguez (Hospital General de Irapuato, Irapuato).

Pakistan. Safdar Ghayur Khan, Dr Farheen Ali (Liaquat National Hospital, Karachi); Badaruddin A. Memon, Gul Hassan Bhutto (Public Sector Hospital Khairpur, Shah Abdul Latif University, Khairpur).

Panama. Fernando G. Alfaro, Cecilia Alvarado, Luz Marina De León, Rodolfo Navarro, José Luis Moreno, Rigoberto Cerrud (Clínica Hospital San Fernando, Panama City).

Peru. Rosa Rosales, Luis Isidro Castillo Bravo, María 
Linares Cáceres (Instituto Nacional de Enfermedades Neoplásicas, Lima); Eduardo Fernández-Maldonado, Manuel Jesús Mayorga Espichan, Liliana Echenique (Clínica San Pablo, Lima); Teodora Atencio-Espinoza, Favio Sarmiento López (Hospital Regional de Pucallpa, Pucallpa); Alex Castañeda-Sabogal, Iliana Paredes Goicochea, Abel Arroyo Sánchez, Guillermo Ríos Alva, Jorge García Ventura, Miguel Ramírez Aguilar, Niler Segura Plasencia, Teófilo Rodríguez (Hospital Victor Lazarte Echegaray, Trujillo).

Philippines. Victoria D. Villanueva, María Corazon V. Tolentino (St. Luke's Medical Center, Quezon City); Regina Berba, Glenn Angelo S. Genuino, Rafael J. Consunji, Jacinto Blas V. Mantaring III (Philippine General Hospital, Manila).

Poland. Wieslawa Duszynska, Teresa Kaiser (University Hospital of Wroclaw, Wroclaw).

Turkey. Saban Esen, Fatma Ulger, Ahmet Dilek, Hava Yilmaz, Canan Aygun, Sukru Küçüködük (Ondokuz Mayis University Medical School, Samsun); Iftihar Koksal, Gürdal Yýlmaz, Selçuk Kaya, Hülya Ulusoy (Karadeniz Technical University School of Medicine, Trabzon); Özay Arıkan Akan, Melek Tulunay, Mehmet Oral, Necmettin Ünal (Ankara University School of Medicine Ibni-Sina Hospital, Ankara); Asu Özgültekin, Asuman Inan (Haydarpasa Numune Training and Research Hospital, Istanbul); Begüm Atasay, Atilla Kiliç, Saadet Arsan (Ankara University School of Medicine, Faculty of Pediatrics, Department of Newborn Medicine); Tanil Kendirli, Erdal Ince, Adem Karbuz, Ergin Çiftçi, Nevin Taşyapar, Melek Güneş (Ankara University School of Medicine, Department of Pediatric Critical Care); Nurettin Erben, Ilhan Ozgunes, Gaye Usluer (Eskisehir Osmangazi University, Eskisehir); Ata Nevzat-Yalcin, Ozge Turhan, Nurgul Gunay, Eylul Gumus, Oguz Dursun (Akdeniz University, Antalya); Sercan Ulusoy, Bilgin Arda, Feza Bacakoglu (Ege University Medical Faculty, Izmir); Fatma Sirmatel, Mustafa Cengiz, Leyla Yilmaz (Harran University, Faculty of Medicine, Sanliurfa); Davut Ozdemir, Mehmet Faruk Geyik, Ahmet Șahin, Selvi Erdogan (Duzce University Medical School Infectious Diseases and Clínical Microbiology, Duzce); Emine Alp, Aysegul Ulu Kilıc (Erciyes University, Faculty of Medicine, Kayseri).

\section{ACKNOWLEDGMENTS}

We thank the many healthcare professionals at each member hospital who assisted with the conduct of surveillance in their hospital, including the surveillance nurses, the clinical microbiology laboratory personnel, and the physicians and nurses providing care for the patients during the study; without their cooperation and generous assistance, this International Nosocomial Infection Control Consortium (INICC) study would not have been possible. We also thank Mariano Vilar, Débora López Burgardt, Santiago Suárez, Denise Brito, Eugenia Manfredi, Luciana Soken, Dario Pizzuto, Ding Yuan, Katie Saunders, and Isaac Kelmeszes, who work at the INICC headquarters in Buenos Aires, for their hard work and commitment to achieving INICC goals; the INICC country coordinators (Altaf Ahmed, Carlos A. ÁlvarezMoreno, Anucha Apisarnthanarak, Luis E. Cuéllar, Bijie Hu, Namita Jaggi, Hakan Leblebicioglu, Eduardo A. Medeiros, Yatin Mehta, Toshihiro Mitsuda, and Lul Raka); the INICC Advisory Board (Carla J. Alvarado, Nicholas Graves, William R. Jarvis, Patricia Lynch, Dennis Maki, Cat Murphy, Russell N. Olmsted, Didier Pittet, Wing Hong Seto, Syed Sattar, and William Rutala), who have so generously supported this unique international infection control network; and especially Patricia Lynch, who inspired us to follow our dreams despite obstacles.

Financial support. Funding for the activities carried out at the INICC headquarters was provided by the corresponding author (V.D.R.) and the Foundation to Fight against Nosocomial Infections.

Potential conflicts of interest. All authors report no conflicts of interest relevant to this article. All authors submitted the ICMJE Form for Disclosure of Potential Conflicts of Interest, and the conflicts that the editors consider relevant to this article are disclosed here.

Address correspondence to Victor D. Rosenthal, MD, MSc, CIC, International Nosocomial Infection Control Consortium (INICC), Corrientes Ave No. 4580, Floor 12, Apt. D, Buenos Aires 1195, Argentina (victor rosenthal@inicc.org, http://www.inicc.org).

\section{REFERENCES}

1. Raju TN. Ignác Semmelweis and the etiology of fetal and neonatal sepsis. J Perinatol 1999;19(4):307-310.

2. Simmons B, Bryant J, Neiman K, Spencer L, Arheart K. The role of handwashing in prevention of endemic intensive care unit infections. Infect Control Hosp Epidemiol 1990;11(11):589-594.

3. Rosenthal VD, Guzman S, Safdar N. Reduction in nosocomial infection with improved hand hygiene in intensive care units of a tertiary care hospital in Argentina. Am J Infect Control 2005; 33(7):392-397.

4. Pittet D, Allegranzi B, Boyce J; World Health Organization World Alliance for Patient Safety First Global Patient Safety Challenge Core Group of Experts. The World Health Organization Guidelines on Hand Hygiene in Health Care and their consensus recommendations. Infect Control Hosp Epidemiol 2009;30(7):611-622.

5. Jarvis WR. Selected aspects of the socioeconomic impact of nosocomial infections: morbidity, mortality, cost, and prevention. Infect Control Hosp Epidemiol 1996;17(8):552-557.

6. Safdar N, Crnich CJ, Maki DG. Nosocomial infections in the intensive care unit associated with invasive medical devices. Curr Infect Dis Rep 2001;3(6):487-495.

7. Rosenthal VD, Maki DG, Graves N. The International Nosocomial Infection Control Consortium (INICC): goals and objectives, description of surveillance methods, and operational activities. Am J Infect Control 2008;36(9):e1-e12.

8. Rosenthal VD, Maki DG, Salomao R, et al. Device-associated nosocomial infections in 55 intensive care units of 8 developing countries. Ann Intern Med 2006;145(8):582-591.

9. Rosenthal VD, Maki DG, Mehta A, et al. International Nosocomial Infection Control Consortium report, data summary for 2002-2007, issued January 2008. Am J Infect Control 2008;36(9): 627-637.

10. Rosenthal VD, Maki DG, Jamulitrat S, et al. International Nosocomial Infection Control Consortium (INICC) report, data summary for 2003-2008, issued June 2009. Am J Infect Control 2010;38(2):95-104.e2.

11. Rosenthal VD, Bijie $H$, Maki DG, et al. International Nosocomial Infection Control Consortium (INICC) report, data summary of 36 countries, for 2004-2009. Am J Infect Control 2012;40(5): 396-407. 
12. Lam BC, Lee J, Lau YL. Hand hygiene practices in a neonatal intensive care unit: a multimodal intervention and impact on nosocomial infection. Pediatrics 2004;114(5):e565-e571.

13. Rosenthal VD, McCormick RD, Guzman S, Villamayor C, Orellano PW. Effect of education and performance feedback on handwashing: the benefit of administrative support in Argentinean hospitals. Am J Infect Control 2003;31(2):85-92.

14. Allegranzi B, Sax H, Bengaly L, et al. Successful implementation of the World Health Organization hand hygiene improvement strategy in a referral hospital in Mali, Africa. Infect Control Hosp Epidemiol 2010;31(2):133-141.

15. Preston GA, Larson EL, Stamm WE. The effect of private isolation rooms on patient care practices, colonization and infection in an intensive care unit. Am J Med 1981;70(3):641-645.

16. Conly JM, Hill S, Ross J, Lertzman J, Louie TJ. Handwashing practices in an intensive care unit: the effects of an educational program and its relationship to infection rates. Am J Infect Control 1989;17(6):330-339.

17. Mayer JA, Dubbert PM, Miller M, Burkett PA, Chapman SW. Increasing handwashing in an intensive care unit. Infect Control 1986;7(5):259-262.

18. Larson EL, Bryan JL, Adler LM, Blane C. A multifaceted approach to changing handwashing behavior. Am J Infect Control 1997;25(1):3-10.

19. Graham M. Frequency and duration of handwashing in an intensive care unit. Am J Infect Control 1990;18(2):77-81.

20. Dubbert PM, Dolce J, Richter W, Miller M, Chapman SW. Increasing ICU staff handwashing: effects of education and group feedback. Infect Control Hosp Epidemiol 1990;11(4):191-193.

21. Dorsey ST, Cydulka RK, Emerman CL. Is handwashing teachable? failure to improve handwashing behavior in an urban emergency department. Acad Emerg Med 1996;3(4):360-365.

22. Boyce JM, Pittet D; Society for Healthcare Epidemiology of America/Association for Professionals in Infection Control/Infectious Diseases Society of America. Guideline for hand hygiene in health-care settings: recommendations of the Healthcare Infection Control Practices Advisory Committee and the HICPAC/ SHEA/APIC/IDSA Hand Hygiene Task Force. MMWR Recomm Rep 2002;51(RR-16):1-45.

23. WHO launches global patient safety challenge; issues guidelines on hand hygiene in health care. Indian J Med Sci 2005;59(10): 461-463.

24. Horan TC, Andrus M, Dudeck MA. CDC/NHSN surveillance definition of health care-associated infection and criteria for specific types of infections in the acute care setting. Am J Infect Control 2008;36(5):309-332.

25. Guinan ME, McGuckin-Guinan M, Sevareid A. Who washes hands after using the bathroom? Am I Infect Control 1997;25(5): 424-425.

26. Haley RW, Bregman DA. The role of understaffing and overcrowding in recurrent outbreaks of staphylococcal infection in a neonatal special-care unit. J Infect Dis 1982;145(6):875-885.

27. Watanakunakorn C, Wang C, Hazy J. An observational study of hand washing and infection control practices by healthcare workers. Infect Control Hosp Epidemiol 1998;19(11):858-860.

28. Lipsett PA, Swoboda SM. Handwashing compliance depends on professional status. Surg Infect (Larchmt) 2001;2(3):241-245.

29. Bischoff WE, Reynolds TM, Sessler CN, Edmond MB, Wenzel
RP. Handwashing compliance by health care workers: the impact of introducing an accessible, alcohol-based hand antiseptic. Arch Intern Med 2000;160(7):1017-1021.

30. Deming W. Out of the Crisis. Boston: MIT Press, 1986.

31. Rosenthal VD, Guzman S, Pezzotto SM, Crnich CJ. Effect of an infection control program using education and performance feedback on rates of intravascular device-associated bloodstream infections in intensive care units in Argentina. Am J Infect Control 2003;31(7):405-409.

32. Rosenthal VD, Guzman S, Safdar N. Effect of education and performance feedback on rates. of catheter-associated urinary tract infection in intensive care units in Argentina. Infect Control Hosp Epidemiol 2004;25(1):47-50.

33. Rosenthal VD, Guzman S, Crnich C. Impact of an infection control program on rates of ventilator-associated pneumonia in intensive care units in 2 Argentinean hospitals. Am J Infect Control 2006;34(2):58-63.

34. Rosenthal VD, Maki DG, Rodrigues C, et al. Impact of International Nosocomial Infection Control Consortium (INICC) strategy on central line-associated bloodstream infection rates in the intensive care units of 15 developing countries. Infect Control Hosp Epidemiol 2010;31(12):1264-1272.

35. Rosenthal VD, Todi SK, Álvarez-Moreno C, et al. Impact of a multidimensional infection control strategy on catheter-associated urinary tract infection rates in the adult intensive care units of 15 developing countries: findings of the International Nosocomial Infection Control Consortium (INICC). Infection 2012;40(5):517-526.

36. Rosenthal VD, Rodrigues C, Álvarez-Moreno C, et al. Effectiveness of a multidimensional approach for prevention of ventilator-associated pneumonia in adult intensive care units from 14 developing countries of 4 continents: findings of the International Nosocomial Infection Control Consortium (INICC). Crit Care Med 2012;40(12):3121-3128.

37. Rosenthal VD, Ramachandran B, Villamil-Gómez W, et al. Impact of a multidimensional infection control strategy on central line-associated bloodstream infection rates in pediatric intensive care units of five developing countries: findings of the International Nosocomial Infection Control Consortium (INICC). Infection 2012;40(4):415-423.

38. Rosenthal VD, Ramachandran B, Dueñas L, et al. Findings of the International Nosocomial Infection Control Consortium (INICC), part I: effectiveness of a multidimensional infection control approach on catheter-associated urinary tract infection rates in pediatric intensive care units of 6 developing countries. Infect Control Hosp Epidemiol 2012;33(7):696-703.

39. Rosenthal VD, Álvarez-Moreno C, Villamil-Gómez W, et al. Effectiveness of a multidimensional approach to reduce ventilatorassociated pneumonia in pediatric intensive care units of 5 developing countries: International Nosocomial Infection Control Consortium findings. Am J Infect Control 2012;40(6):497-501.

40. Rosenthal VD, Rodríguez-Calderón ME, Rodríguez-Ferrer M, et al. Findings of the International Nosocomial Infection Control Consortium (INICC), part II: impact of a multidimensional strategy to reduce ventilator-associated pneumonia in neonatal intensive care units in 10 developing countries. Infect Control Hosp Epidemiol 2012;33(7):704-710. 